\title{
Annularins I and J: New Metabolites Isolated from Endophytic Fungus Exserohilum rostratum
}

\author{
Eduardo A. A. Pinheiro, ${ }^{a}$ Fabio C. Borges, ${ }^{a}$ Jeferson R. S. Pina, ${ }^{a}$ Leila R. S. Ferreira, ${ }^{a}$ \\ Jorgeffson S. Cordeiro, ${ }^{a}$ Josiwander M. Carvalho, ${ }^{a}$ André O. Feitosa, ${ }^{a}$ \\ Francinete R. Campos, ${ }^{b}$ Andersson Barison, ${ }^{c}$ Afonso D. L. Souza, ${ }^{d}$ \\ Patrícia S. B. Marinho ${ }^{a}$ and Andrey M. R. Marinho ${ }^{*}, a$ \\ ${ }^{a}$ Faculdade de Química, Universidade Federal do Pará, 66075-110 Belém-PA, Brazil \\ ${ }^{b}$ Departamento de Farmácia and 'Departamento de Química, Universidade Federal do Paraná, \\ 80060-000 Curitiba-PR, Brazil \\ ${ }^{d}$ Departamento de Química, Universidade Federal do Amazonas, 69077-000 Manaus-AM, Brazil
}

\begin{abstract}
The paper describes the isolation of ergosterol peroxide, monocerin, annularin I and annularin $\mathrm{J}$ compounds of Exserohilum rostratum biomass extracts. Compounds were isolated by silica gel column chromatography in polarity gradient and the structures were determined by nuclear magnetic resonance (NMR) and mass spectrometry (MS) methods. Monocerin, annularin I and annularin J compounds were tested against Escherichia coli, Pseudomonas aeruginosa and Bacillus subtilis bacteria and showed moderate activity. Annularin I and annularin J compounds are new natural products.
\end{abstract}

Keywords: annularins, polyketides, E. rostratum, endophytic fungi

\section{Introduction}

Endophytic microorganisms live in plants internal tissues without causing apparent disease to their hosts. ${ }^{1}$ Endophyte microbial colonization can be demonstrated by isolating plant tissues disinfected through histological cut and by DNA amplification technique. ${ }^{2}$

In tropical and temperate forests (which cover only $1.5 \%$ of the terrestrial surface), there are approximately 300,000 (three hundred thousand) plant species analyzed so far, homing more than $60 \%$ of the world's biodiversity. ${ }^{3}$ Extreme diversity allows for the opportunity to discover new microorganisms that may be potential bioactive compounds producers for agriculture, industry and medicine. ${ }^{4}$

There is a great interest in the study of endophytic microorganisms, including their application in pest biocontrol. Fungi are good secondary metabolite producers, and many have the same biological activity, ${ }^{5-8}$ especially polyketides. For example, the polyketide citrinin isolated from Penicillium janthinellum completely inhibited the growth of Leishmania braziliensis. ${ }^{9}$ Some fungi species

*e-mail: andrey@ufpa.br of Penicillium and Pestalotiopsis genera produce high diversity of polyketides with antimicrobial activity. ${ }^{10,11}$

In another study with a variety of endophytes isolated from Vigueira arenaria and Tithonia diversifolia fungal extracts, important antiparasitic and antimicrobial activities were observed in fungal extracts. ${ }^{12}$ In the Nodulisporium sp. (Xylariaceae) fungus extract, which was isolated from the woody plant species Erica arborea (Ericaceae), nodulisporina D, E and F compounds were obtained, having antifungal, antibacterial and algaecide activity. ${ }^{13}$ From the endophytic fungus Ampelomyces sp., isolated from the medicinal plant Urospermum picroides (Asteraceae), 6-O-methylalaternina and altersolanol A compounds were isolated, which showed antimicrobial activity against Gram-positive pathogens Staphylococcus aureus, S. epidermidis and Enteorococcus faecalis. ${ }^{14}$

Brazil is estimated to be home of about $20 \%$ of the world's biodiversity and is considered the country in the world with the largest number of endemic species. ${ }^{15}$ About 270,000 plant species on this planet are estimated to harbor about 13.6 million unique endophytic fungal species, in addition to approximately 100,000 fungi species already known to date. Therefore, there are great chances of finding 
new substances produced by endophytic fungi that may have some useful biological property. ${ }^{16}$

The fungus Exserohilum rostratum was isolated as an endophyte from Bauhinia guianensis, a typical Amazon plant that is used by the local population to treat infections, diabetes and painful processes. The present work describes the isolation and structural identification of ergosterol peroxide (1), monocerin (2), annularin I (3) and annularin J (4) compounds obtained from E. rostratum biomass extracts (Figure 1). Annularin I (3) and annularin $\mathrm{J}(4)$ compounds are new natural products.

\section{Experimental}

\section{General procedures}

High resolution mass spectra were obtained in positive ion mode, using a micrOTOF-Q (Bruker Daltonics, USA) mass spectrometer equipped with an electrospray ionization (ESI) source. Low resolution mass spectra were obtained in positive ion mode, using a TSQ Quantum Access Thermo ${ }^{\circledR}$ (Thermo Fisher Scientific, UK) instrument. 1D and 2D nuclear magnetic resonance (NMR) spectra were recorded on a Varian Mercury 300 (Varian, Inc., USA) spectrometer using solvent signal (d-chloroform) as reference. Chemical shifts were given in delta $(\delta)$ values and the coupling constants $(J)$ were given in Hertz $(\mathrm{Hz})$.

\section{Microorganism isolation}

General procedures adopted for microorganism isolation followed the methodology described by Marinho et al. ${ }^{17}$ After collection, B. guianensis healthy tissues were washed with water and their surface was sterilized by immersion in $70 \%$ aqueous ethanol ( $1 \mathrm{~min}$ ), followed by $5 \%$ aqueous sodium hypochlorite (4 min), and finally with 70\% aqueous ethanol (30 s). Afterwards, tissues were rinsed with sterilized water. The latter water was incubated in Petri dishes, in order to guarantee the elimination of all epiphytic microorganisms. Small tissues pieces were excised and placed in Petri dishes containing potato dextrose agar (PDA) medium at $30{ }^{\circ} \mathrm{C}$. Individual hyphal tips of the emerging fungi were removed and replaced on PDA. The ER1.11 strain was identified as Exserohilum rostratum by DNA sequencing at the Instituto de Ciências Biológicas at Universidade Federal do Pará (UFPA, Belém, Brazil). A voucher specimen has been deposited at Laboratório de Bioensaios e Química de Micro-organismos (LaBQuiM, UFPA).<smiles>CCC[C@H]1C[C@H]2OC(=O)c3c(cc(OC)c(OC)c3O)[C@]2(C)O[C@@H](/C=C/C(C)C(C)C)CCC1[C@H](C)/C=C/C(C)C(C)C</smiles><smiles>CCCCc1oc(=O)cc(OC)c1C</smiles><smiles>CCCCc1oc(=O)cc(OC)c1CO</smiles>

Figure 1. Compounds isolated from E. rostratum. 


\section{E. rostratum culture in rice and compounds isolation}

Twenty-five Erlenmeyer flasks $(500 \mathrm{~mL})$ containing $90 \mathrm{~g}$ of rice (Uncle Ben's ${ }^{\circledR}$ ) and $75 \mathrm{~mL}$ of distilled water per flask were autoclaved during $45 \mathrm{~min}$ at $121^{\circ} \mathrm{C}$. Small cubes of PDA medium containing E. rostratum mycelium were added to 22 Erlenmeyer flasks under sterile condition. Three flasks were used as controls. After 25 days of growth at $25^{\circ} \mathrm{C}$, the biomass obtained was macerated with hexane, ethyl acetate and methanol. Solutions obtained were concentrated in a rotary evaporator, in order to obtain the biomass extracts. From the ethyl acetate extract, after successive fractionations on silica gel chromatographic column eluted with hexane, ethyl acetate and methanol in a polarity gradient, ergosterol peroxide (35 mg) (1), monocerin (80 mg) (2), annularin I (10 mg) (3) and annularin $\mathrm{J}$ (5 mg) (4) compounds were purified.

\section{Antimicrobial test}

Microorganisms susceptibility to the test compounds were determined by microbroth dilution assay as recommended by the Subcommittee on Antifungal Susceptibility Testing of the US National Committee for Clinical Laboratory Standards. ${ }^{18}$ Tests were performed on 96 well plates with $100 \mu \mathrm{L}$ of Mueller Hinton broth (MHB), $100 \mu \mathrm{L}$ of test compound and $5 \mu \mathrm{L}$ of test bacteria at $1.0 \times 10^{8} \mathrm{CFU} \mathrm{mL}^{-1}$, followed by incubation at $37{ }^{\circ} \mathrm{C}$ ( $24 \mathrm{~h})$. Test substances obtained from the fungal culture were dissolved in dimethyl sulfoxide with initial concentration of $500 \mu \mathrm{g} \mathrm{mL}^{-1}$. Test microorganisms were Escherichia coli (ATCC 25922), Pseudomonas aeruginosa (ATCC 27853) and Bacillus subtilis (ATCC 6633), which were obtained from Instituto Evandro Chagas, Belém, PA, Brazil. Bioactivity was registered as red coloration absence in the wells after addition of $10 \mu \mathrm{L}$ 2,3,5-triphenyltetrazolium chloride. Penicillin, vancomycin and tetracycline $\left(25 \mu \mathrm{g} \mathrm{mL}^{-1}\right.$ each) were used as positive controls; the culture medium (MHB only) was used as negative control.

\section{Annularin I (3)}

Colorless oil; ${ }^{1} \mathrm{H}$ NMR and ${ }^{13} \mathrm{C}$ NMR data (see Table 1); HRESIMS $[\mathrm{M}+\mathrm{H}]^{+}$calcd. for $\mathrm{C}_{11} \mathrm{H}_{16} \mathrm{O}_{3}: 197.1177$; found: 197.1210. LRAPCIMS (daughter ion, $20 \mathrm{eV}) \mathrm{m} / \mathrm{z}: 197$ $\left([\mathrm{M}+\mathrm{H}]^{+}, 45 \%\right), 153$ (26), 139 (27), 125 (60), 109 (100).

Annularin $\mathrm{J}(4)$

Colorless oil; ${ }^{1} \mathrm{H}$ NMR and ${ }^{13} \mathrm{C}$ NMR data (see Table 1); HRESIMS [M + H] $]^{+}$calcd. for $\mathrm{C}_{11} \mathrm{H}_{16} \mathrm{O}_{4}: 213.1095$; found: 213.1132. LRAPCIMS (daughter ion, $20 \mathrm{eV}$ ) $\mathrm{m} / \mathrm{z}: 213$ $\left([\mathrm{M}+\mathrm{H}]^{+}, 22 \%\right), 153$ (100), 141 (22), 125 (70).

\section{Results and Discussion}

Compound 1 was isolated from the apolar fractions of the ethyl acetate extract in amorphous white solid form, and its ${ }^{1} \mathrm{H}$ and ${ }^{13} \mathrm{C}$ NMR data showed the identity of the ergosterol peroxide steroid, ${ }^{17}$ which is an steroid commonly isolated from fungi and reported to have anticancer activity. ${ }^{19}$

Monocerin (2), the major metabolite, was characterized by spectroscopic data analyzes and comparison with data reported in the literature. Monocerin has been isolated from several fungal species, including Helminthosporium monoceras, Exserohilum turcum, Fusarium larvarum and Microdochium bolleyi as an antifungal, insecticidal, and phytotoxic secondary metabolite. $^{20}$

Compound 3 molecular formula was determined as $\mathrm{C}_{11} \mathrm{H}_{16} \mathrm{O}_{3}$ by high-resolution electrospray ionization mass spectrometry (HRESIMS) $\left(\mathrm{m} / \mathrm{z} 197.1210[\mathrm{M}+\mathrm{H}]^{+}\right.$, calcd. 197.1177). ${ }^{1} \mathrm{H}$ NMR spectrum of $\mathbf{3}$ showed signals related hydrocarbon side chain, a methoxy group and olefinic methine unit presence. In addition, there was a singlet $\delta 2.19$ signal, attributed to methyl attached to on $\mathrm{sp}^{2}$ carbon. Annularin I (3) structure was solved through 2D NMR data analysis. Signals were observed for four $\mathrm{sp}^{2}$ double bond carbons at $\delta 87.8$ (C-2), $170.9(\mathrm{C}-3), 111.7$ (C-4), and 157.9 (C-5). C-2 carbon, according to heteronuclear correlations (HETCOR), is correlated with the $\mathrm{H}-2(\delta 5.44, \mathrm{~s})$ hydrogen. ${ }^{13} \mathrm{C}$ NMR spectrum also showed a signal at $\delta 164.8$ assigned to the lactone group carbonyl $(\mathrm{C}-1)$. The only olefinic proton $\mathrm{H}-2$ ( $\delta$ 5.44) showed heteronuclear multiple bond correlations (HMBC) with C-1, C-3, and C-4. These data, along with the high chemical shifts of C-2 and C-3 (87.8 and 170.9), suggested the presence of the $\beta$-oxygenated $\alpha, \beta$ - unsaturated ester unit, shown in 3. The methoxyl group OMe-10 shows strong correlation with $\delta 170.9$, which allowed OMe-10 to position at C-3. Me-11 methyl was positioned at $\mathrm{C}-4$, and was also correlated with $\delta 157.9$ (C-5) in HMBC. The hydrocarbon side chain was attached to $\mathrm{C}-5$ based on HMBC correlations between H-6 and C-4 and between H-7 and C-5. Carbonyl carbon C-1 and oxygenated $\mathrm{sp}^{2}$ carbon $\mathrm{C}-5$ must be linked through the remaining oxygen atom to form an $\alpha$-pyrone ring, in order to complete annularin I (3) structural assignment (Figure 2).

Compound 4 showed significant spectral similarities to the compound $\mathbf{3}$, indicating that there were structurally similar compounds. Annularin J (4) has $\mathrm{C}_{11} \mathrm{H}_{16} \mathrm{O}_{4}$ molecular formula proposed on NMR and MS data, $m / z, 213.1132$ $[\mathrm{M}+\mathrm{H}]^{+}$(calcd. 213.1095). In the ${ }^{1} \mathrm{H}$ NMR spectrum of 4, the signal for methyl Me-11 ( $\delta$ 2.19) was replaced by a signal at $\delta 4.44(\mathrm{~s}, 2 \mathrm{H})$. In addition, the signal for the methyl Me-11 ( $\delta$ 17.1) was replaced by a signal at $\delta 58.8$, 


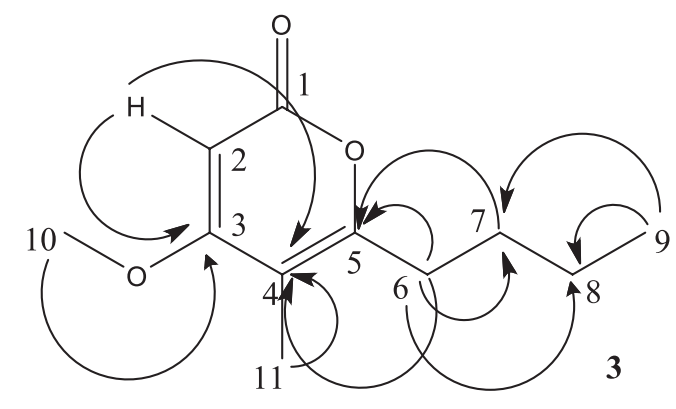<smiles>CCCCc1oc(=O)c(CCC=O)c(OC)c1CO</smiles>

Figure 2. HMBC correlations of annularin I (3) and annularin J (4) isolated from E. rostratum.

which by the distortionless enhancement by polarization transfer (DEPT) experiment it is a $\mathrm{CH}_{2}$ group. This carbon $(\delta 58.8$ ) is correlated with hydrogen $\delta 4.44$ in HETCOR. Data show that the Me-11 methyl was oxidized to $-\mathrm{CH}_{2} \mathrm{OH}$ alcohol, which was confirmed by the HMBC correlations of $\delta 4.44$ (H-11) with carbons $\delta 170.7$ (C-3) and 157.5 (C-5). This information led to identification of the structure of $\mathbf{4}$ as shown, which only differs from $\mathbf{3}$ by hydroxyl group (Figure 2).

NMR data of $\mathbf{3}$ and $\mathbf{4}$ were compared with literature data, which showed that they belong to the polyketides class called annularins. ${ }^{21}$ Compounds $\mathbf{3}$ and $\mathbf{4}$ are different from annularins D and B by an added carbon in their side chains. Pyrones isolated from fungi are polyketides. Thus, the biosynthetic origin of compounds $\mathbf{3}$ and $\mathbf{4}$ might result from methylation of a tetraketide or decarboxylation of a pentaketide giving an additional carbon in the side chain. ${ }^{22}$ Difference was confirmed by ${ }^{1} \mathrm{H}$ and ${ }^{13} \mathrm{C}$ NMR data and mass spectra. Substance 3 showed $m / z 197$ and the substance 4 $\mathrm{m} / \mathrm{z} 213$ in the low resolution atmospheric pressure chemical ionization mass spectrometry LRAPCIMS (+). Compounds $\mathbf{3}$ and $\mathbf{4}$ are novel natural products and have been called annularin I (3) and annularin $\mathrm{J}(\mathbf{4}) .{ }^{1} \mathrm{H}$ and ${ }^{13} \mathrm{C}$ NMR data for $\mathbf{3}$ and $\mathbf{4}$ are shown in Table 1.

Table 1. ${ }^{1} \mathrm{H}$ and ${ }^{13} \mathrm{C}$ NMR data for compounds 3 and $4\left(300 \mathrm{MHz}, \mathrm{CDCl}_{3}\right)$

\begin{tabular}{lcccc}
\hline No. & \multicolumn{3}{c}{$\mathbf{3}$} & \multicolumn{2}{c}{$\mathbf{4}$} \\
\cline { 2 - 5 } & ${ }^{1} \mathrm{H}\left(\mathrm{mult}, J_{H}\right)$ & ${ }^{13} \mathrm{C}$ & ${ }^{1} \mathrm{H}\left(\right.$ mult, $\left.J_{H}\right)$ & ${ }^{13} \mathrm{C}$ \\
\hline 1 & & 164.8 & & 164.1 \\
2 & $5.44(\mathrm{~s})$ & 87.8 & $5.51(\mathrm{~s})$ & 89.3 \\
3 & & 170.9 & & 170.7 \\
4 & & 111.7 & & 113.1 \\
5 & & 157.9 & & 157.5 \\
6 & $2.30(\mathrm{t}, 6.9)$ & 23.9 & $2.37(\mathrm{t}, 6.9)$ & 23.3 \\
7 & $1.39(\mathrm{~m})$ & 31.4 & $1.39(\mathrm{~m})$ & 32.1 \\
8 & $1.33(\mathrm{~m})$ & 22.6 & $1.35(\mathrm{~m})$ & 22.4 \\
9 & $0.90(\mathrm{t}, 6.9)$ & 13.8 & $0.91(\mathrm{t}, 6.9)$ & 13.8 \\
10 & $3.80(\mathrm{~s})$ & 56.0 & $3.83(\mathrm{~s})$ & 56.2 \\
11 & $2.19(\mathrm{~s})$ & 17.1 & $4.44(\mathrm{~s})$ & 58.8 \\
\hline
\end{tabular}

Compounds 2, $\mathbf{3}$ and $\mathbf{4}$ showed moderate antimicrobial action. The polyketide monocerin (2) was the most active and the only one that inhibited P. aeruginosa growth, showing bacteriostatic effect up to $62.5 \mu \mathrm{g} \mathrm{mL}{ }^{-1}$. Annularin I (3) and annularin $\mathbf{J}$ (4) were not active against $P$. aeruginosa and showed moderate activity against $E$. coli and B. subtilis. Compound 3 showed effect on Escherichia coli and Bacillus subtilis growth at 62.50 and $31.25 \mu \mathrm{g} \mathrm{mL} L^{-1}$. Compound 4 showed weak effect on Escherichia coli and Bacillus subtilis growth at $62.50 \mu \mathrm{g} \mathrm{mL}^{-1}$.

\section{Conclusion}

E. rostratum chemical investigation resulted in the isolation of two new compounds, annularin I and annularin J. Isolated compounds were tested against Escherichia coli, Pseudomonas aeruginosa and Bacillus subtilis, showing moderate activity.

\section{Supplementary Information}

Supplementary information containing 1D and 2D NMR, and MS data for annularins I and $\mathbf{J}$ is available free of charge at http://jbcs.sbq.org.br as a PDF file.

\section{Acknowledgments}

The authors thank the Fundação Amazônia de Amparo a Estudos e Pesquisas do Pará (FAPESPA), Conselho Nacional de Desenvolvimento Científico e Tecnológico (CNPq), Coordenação de Aperfeiçoamento de Pessoal de Ensino Superior (CAPES) and Ministério da Saúde (MS) for financial support.

\section{References}

1. Zhao, J.; Zhou, L.; Wang, J.; Shan, T.; Zhong, L.; Liu, X.; Gao, X.; Curr. Res. Technol. Educ. Top. Appl. Microbiol. Microb. Biotechnol. 2010, 1, 567.

2. Stone, J. K.; Bacon, C. W.; Withe-Jr, J. F. In Microbial 
Endophytes; Bacon, C. W.; White-Jr, J. F., eds.; Marcel Dekker: New York, 2000, ch. 1.

3. Strobel, G. A.; Daisy, B.; Castillo, U.; Harper, J.; J. Nat. Prod. 2004, 67, 257.

4. Strobel, G. A.; Nat. Prod. Rep. 2014, 31, 259.

5. Rosa, L. H.; Gonçalves, V. N.; Caligiorne, R. B.; Alves, T. M. A.; Rabello, A.; Sales, P. A.; Romanha, A. J.; Sobral, M. E. G.; Rosa, C. A.; Braz. J. Microbiol. 2010, 41, 420.

6. Chandra, S.; Appl. Microbiol. Biotechnol. 2012, 95, 47.

7. Pinheiro, E. A. A.; Carvalho, J. M.; Santos, D. C. P.; Feitosa, A. O.; Marinho, P. S. B.; Guilhon, G. M. S. P.; Santos, L. S.; Souza, A. L. D.; Marinho, A. M. R.; An. Acad. Bras. Cienc. 2013, 85, 1247.

8. Samaga, P. V.; Rai, V. R.; Ann. Microbiol. (Heidelberg, Ger.) 2016, 66, 229.

9. Marinho, A. M. R.; Rodrigues-Filho, E.; Ferreira, A. G.; Santos, L. S.; J. Braz. Chem. Soc. 2005, 16, 1342.

10. Pestre, R.; Marinho, A. M. R.; Rodrigues-Filho, E.; Quim. Nova 2007, 30, 1867.

11. Oliveira, M. N.; Santos, L. S.; Guilhon, G. M. S. P.; Santos, A. S.; Ferreira, I. C. F.; Lopes Jr, M. L.; Arruda, M. S. P.; Marinho, A. M. R.; Silva, M. N.; Rodrigues Filho, E.; Oliveira, M. C. F.; J. Braz. Chem. Soc. 2011, 22, 993.

12. Guimarães, D. O.; Borges, W. S.; Kawano, C. Y.; Ribeiro, P. H.; Goldman, G. H.; Nomizo, A.; Thiemann, O. H.; Oliva, G.; Lopes, N. P.; Pupo, M. T.; FEMS Immunol. Med. Microbiol. 2008, 52, 134.
13. Dai, J.; Krohn, K.; Draeger, S.; Schulz, B.; Eur. J. Org. Chem. 2009, 10, 1564.

14. Aly, A. H.; Debbab, A.; Kjer, J.; Proksch, P.; Fungal Divers. 2010, $41,1$.

15. Barreiro, E. J.; Bolzani, V. S.; Quim. Nova 2009, 32, 679.

16. Kumar, D. S. S.; Hyde, K. D.; Fungal Divers. 2004, 17, 69.

17. Marinho, A. M. R.; Marinho, P. S. B.; Rodrigues-Filho, E.; Quim. Nova 2009, 32, 1710.

18. National Committee for Clinical Laboratory Standards; Methods for Dilution and Antimicrobial Susceptibility Tests for Bacteria that Grow Aerobically; NCCLS Approved Standard M7-A4: Wayne, PA, 1997.

19. Kang, J. H.; Jang, J. E.; Mishra, S. K.; Lee, H. J.; Nho, C. W.; Shin, D.; Jin, M.; Kim, M. K.; Choi, C.; Oh, S. H.; J. Ethnopharmacol. 2015, 173, 303.

20. Sappapan, R.; Sommit, D.; Ngamrojanavanich, N.; Pengpreecha, S.; Wiyakrutta, S.; Sriubolmas, N.; Pudhom, K.; J. Nat. Prod. 2008, 7, 1657.

21. Li, C.; Nitka, M. V.; Gloer, J. B.; Campbell, J.; Shearer, C. A.; J. Nat. Prod. 2003, 66, 1302.

22. Pedras, M. S. C.; Chumala, P. B.; Phytochemistry 2005, 66, 81.

Submitted: February 2, 2016

Published online: May 5, 2016 